\title{
Poverty of the Elderly in Korea
}

\author{
Se Won $\operatorname{Kim}^{1} \&$ Jai S. Mah ${ }^{1}$ \\ ${ }^{1}$ Ewha Womans University, Seoul, South Korea \\ Correspondence: Professor Jai S. Mah, Division of International Studies, Ewha Womans University, Seodaemun-gu, \\ Seoul 03760, South Korea. E-mail: jsmah@ewha.ac.kr \\ Received: November 18, 2020 \\ Accepted: December 9, 2020 \\ Online Published: January 20, 2021 \\ doi:10.5430/rwe.v12n2p146 \\ URL: https://doi.org/10.5430/rwe.v12n2p146
}

\begin{abstract}
Korea's elderly poverty rate remains very high. The fact that a society long governed by the Confucian idea of respect for the elderly has a high elderly poverty rate is ironic. This paper reveals the causes of the exceptionally high poverty rate of the elderly in Korea. Significant reductions in the birth rate and the rapid aging of the population have fueled reductions in private transfers from adult children to elderly parents. Efforts to strengthen the public transfer system have not kept pace with reductions in private transfers in relieving elderly poverty. Korea's experience provides policy implications to developing countries.
\end{abstract}

Keywords: elderly, poverty, Korea, Confucianism

\section{Introduction}

Outward-oriented industrialization has enabled Korea to enjoy unprecedented economic growth since the mid-1960s. However, this rapid economic growth has also given rise to certain social issues. The Korean government introduced the family planning program on a national scale in 1962; the plan encouraged Korean families to have fewer children, as the Korean government viewed reducing the fertility rate as a core means of promoting economic development between the 1960s and the 1980s (Choi, 2009). Fertility and mortality rates have decreased ever since, while overall life expectancy at birth jumped from 62 years in 1970 to 83 years in 2017 (Statistics Korea, 2019).

Korea's sudden modernization led to a sharp decline in extended family cohabitation and an increase in nuclear families. This is partly attributed to the fact that members of older generations have preferred to reside in their rural hometowns, while members of younger generations have moved to large cities (Jung, 2018). The economic crisis in the late 1990s further weakened family traditions. Increasing poverty, inequality, and unemployment led fewer individuals to follow the traditional customs of caring for and financially supporting their old parents. This left many elderly persons without any familial support. Together with the phenomenon of rapid population aging, such changes have led to the very high poverty rate among the elderly in Korean society.

Rapid population aging and low birth rate are conspicuous phenomena in Korean society. The birth rate fell continuously from 4.53 in 1970 to 0.98 in 2018 . The ratio of elderly people in the population-i.e., the number of people aged 65 or over divided by the total population - rose from 2.9 percent in 1960 to 5.1 percent in 1990 and then to 14.3 percent in 2018. In 2018, the number of elderly individuals in Korea reached 7.4 million out of a total population of 51.6 million. By 2040, the elderly population is expected to comprise 33.9 percent of the total population, a projection that highlights the rapid expansion of the aging population in Korea. In addition, although the old-age dependency ratio, which can be defined as the number of individuals aged 65 or over divided by the number of individuals between the ages of 20 and 64 (Statistics Korea, 2019), was as low as 5.3 percent in 1960, it continued to rise to 7.4 percent in 1990 and then to 19.6 percent in 2018, and it is expected to reach 60.1 percent by 2040 (Statistics Korea, 2019). This indicates that it has become very hard for young and middle-aged citizens to support the elderly.

Unlike in Korea and many developing countries, population aging has progressed gradually in most developed countries. This has allowed these countries to accumulate enough resources to establish social welfare and pension systems over long periods of time. Moreover, gradual industrialization has enabled most developed countries to retain traditional societal structures while adjusting policies to changing societal situations. Meanwhile, rapid economic growth and demographic changes have left Korean society less prepared to tackle the social issues related to rapid population aging (United Nations Economic and Social Commission for Asia and the Pacific (UNESCAP), 
2015). Indeed, the lack of a solid social welfare system has led to very high poverty and suicide rates among the elderly in Korea.

Despite rapid economic growth and a general increase in per capita income, the issue of the elderly poverty in Korea has long been overlooked; indeed, only recently has it begun to receive the attention it warrants. The adverse consequences of the economic crisis in late 1990s along with the population aging have further exacerbated elderly poverty. These trends have brought social awareness to the issue, highlighting the urgent need for a remedy. Despite governmental efforts to strengthen the public transfer system to support impoverished elderly individuals, Korea currently has the highest elderly poverty rate as well as the highest elderly suicide rate out of all OECD members. The fact that Korean society, which has long maintained a Confucian culture that prioritizes respect for the elderly, has such high elderly poverty and elderly suicide rates is deeply ironic. The aims of this paper are to explain Korea's high elderly poverty rate, identify the factors that have caused it, and to derive policy implications based on Korea's experience. To do so, Section 2 describes the current state of the elderly poverty in Korea. Sections 3 and 4 explain the private transfer and the public transfer affecting the elderly poverty, respectively. Conclusions and policy implications are provided in section 5.

\section{Elderly Poverty in Korea}

Confucian ethics, which identify filial piety and unconditional respect for the elderly as well as one's parents as a virtue, have shaped many of the social norms in the Korean society. Paradoxically, however, Korea has the highest elderly poverty rate among all OECD members. Table 1 shows the exceptionally high poverty rate of the elderly population in Korea. In Korea, the relative poverty rate, which is defined as the ratio of the number of people whose income falls below the poverty line, taken as half the median household income of the total population (OECD, 2019b), of the overall population is 17.4 percent, 6.1 percent higher than the OECD average of 11.3 percent. Out of 38 countries reported by OECD (2019), Korea ranks fifth in terms of the total population poverty rate, followed by South Africa (26.6 percent), Costa Rica (20.4 percent), Israel (17.9 percent), and the US (17.8 percent).

Table 1. International comparison of poverty rates, 2017 or 2018

(unit: percent)

\begin{tabular}{lll}
\hline country & total population & 66 years or more \\
\hline Australia & 12.1 & 23.2 \\
Canada & 12.4 & 10.5 \\
Costa Rica & 20.4 & 25.5 \\
Czech Republic & 5.6 & 4.5 \\
France & 8.3 & 3.4 \\
Germany & 10.4 & 9.6 \\
Greece & 14.4 & 7.8 \\
Hungary & 10.1 & 8.6 \\
Israel & 17.9 & 19.9 \\
Japan & 15.7 & 19.6 \\
Korea & 17.4 & 43.8 \\
Poland & 10.3 & 9.3 \\
Portugal & 12.5 & 9.5 \\
South Africa & 26.6 & 20.7 \\
Spain & 15.5 & 9.4 \\
Turkey & 17.2 & 17.0 \\
U.K. & 11.1 & 14.2 \\
U.S. & 17.8 & 22.9 \\
\hline OECD average & 11.3 & 12.6 \\
\hline
\end{tabular}

Source: OECD, Poverty Rate, Retrieved August 27, 2019, from http://data.oecd.org/inequality/poverty-rate.htm. 
Meanwhile, the poverty rate for the elderly population - that is, the population comprised of individuals aged 65 or over-in Korea is higher than that of any other OECD country, at 43.8 percent. In other words, almost half of the old-age population in Korea falls below the relative poverty line. Compared to other age groups whose poverty rates are more or less the same as the OECD averages over the years, the elderly poverty rate in Korea is exceptionally high. Indeed, the elderly poverty rate in Korea is about 3.5 times higher than the OECD average elderly poverty rate of 12.6 percent. While elderly poverty is already prevalent within Korean society, the fast pace of population aging in Korea will lead even more elderly people to be exposed to poverty in the near future.

Table 2 shows the relative poverty rates for each age group when the total relative poverty rate is set at 100 . One notable feature is the fact that the poverty rates in Korea increase with the age groups. The poverty rates of the other age groups in Korea are rather evenly distributed below 22 percent, thus ranging close to both the overall poverty rate of Korea and the OECD average. However, the relative poverty rate of the group aged 66-75 is almost three times higher than the total poverty rate of Korea and the OECD average.

Table 2. Relative poverty rates by age group

\begin{tabular}{lll}
\hline age group & Korea in 2011 & OECD Average in 2010 \\
\hline below 18 & 64 & 116 \\
$18-25$ & 69 & 128 \\
$26-40$ & 47 & 90 \\
$41-50$ & 59 & 80 \\
$51-65$ & 114 & 85 \\
$66-75$ & 300 & 99 \\
above 75 & 340 & 120 \\
\hline
\end{tabular}

Note: Poverty rate for the entire population is set at 100.

Sources: OECD (2014). Economic Surveys: Korea. Paris: OECD.

Moreover, over the decades, the elderly poverty rate in terms of the OECD average converges toward the total poverty rate. While the poverty rate of the group aged 66-75 was 113 percent of the total population's poverty rate in the mid-1980s, it fell to 99 percent of the total population's poverty rate in 2010. Similarly, the poverty rate of the elderly group aged over 75 was 165 percent of the total population's poverty rate in the mid-1980s, but declined over the years to 120 percent of the total population's poverty rate in 2010 (OECD, 2019a). Meanwhile, unlike the OECD average, the elderly poverty rate in Korea deviated further from the total poverty rate of 15.2 percent from 2006 to 2011. The poverty rate for those over 75 is almost 3.5 times higher than the total poverty rate of 15.2 percent in Korea, while that of the OECD average remains close to 11.5 percent, its total poverty rate (OECD, 2014).

The severity of elderly poverty is also reflected in the high suicide rate among Korea's elderly population. Table 3 compares elderly suicide rates per 100,000 persons in selected OECD member countries from 2005 to 2015. Notably, Korea has by far the highest elderly suicide rate among all OECD members regardless of age group, which is a very peculiar social phenomenon. In 2005, the suicide rate in Korea in the 75 or over age group (65-74) was about eight (five) times higher than that of the OECD average. Although the elderly suicide rate in Korea has since decreased slightly, it remains the highest among OECD members; indeed, depending on age group, it currently either more than doubles or is four times higher than the OECD average. National surveys conducted by the Korea Institute for Health and Social Affairs (KIHASA) in 2017 identified economic issues as the leading motivation for suicide attempts, accounting for 27.7 percent of all attempts, followed by health and disconnection/conflicts with family, which accounted for 27.6 percent and 18.6 percent, respectively (KIHASA, 2017). 
Table 3. International comparison of the suicide rate of the elderly

\begin{tabular}{llcll}
\hline country & \multicolumn{4}{c}{ year (age) } \\
& \multicolumn{3}{c}{2005} & \multicolumn{2}{c}{2015} \\
& $(65-74)$ & $(75+)$ & $(65-74)$ & $(75-79)$ \\
\hline Korea & 81.8 & 160.4 & 57.6 & 149.0 \\
Austria & 23.4 & 21.6 & 27.5 & 71.7 \\
France & 21.3 & 18.9 & 27.1 & 43.0 \\
Japan & 17.9 & 14.6 & 33.7 & 37.7 \\
U.S. & 14.1 & 11.7 & 28.6 & 40.4 \\
Germany & 12.5 & 16.1 & 29.7 & 52.4 \\
Canada & 10.5 & 7.3 & 17.5 & 24.5 \\
Netherlands & 7.5 & 9.5 & 19.0 & 21.7 \\
U.K. & 4.8 & 3.8 & 11.2 & 9.8 \\
\hline OECD average & 16.3 & 19.3 & 24.2 & 35.4
\end{tabular}

Sources: OECD (2005, 2015a). Society at a Glance.

Korean customs of respecting and caring for one's elderly parents long shaped various aspects of Korean society. In particular, adult children have played a dominant role in financially supporting their elderly relatives. Under the influence of Confucianism, filial piety and the act of respecting one's seniors were widely honored in Korean society. However, the introduction of modern values such as individualism caused such traditional customs to quickly fade. Although adult children remain important sources of income for their aging parents, financial support from adult children has rapidly decreased. Moreover, despite this change, the development of a public transfer system to support the elderly has been slow. Thus, Korea faces two major challenges in tackling elderly poverty-that is, the sudden decrease in adult children's financial support for their elderly parents and an insufficient public transfer system to offset the decrease in private transfers.

\section{Private Transfer}

Under the influence of Confucianism, respect for one's elderly parents was long considered a moral duty in Korea. Indeed, filial piety, hyo, served as the basis for family structures and inter-generational relationships throughout Korean society. It motivated the formation of the traditional income structure for the elderly, in which private transfers from families played a major role. Familial support has not only been customary, but has also been a mutual concept in Korea. It was taken for granted that while parents would financially support the education and growth of their children until they married, adult children would provide their parents financial and emotional support once they acquired stable employment. Thus, inter-generational transfers were customary in Korea - a fact that the income and family structures in Korea still reflect. Korean households show significantly higher levels of private transfers than households in other countries. Co-residence among generations has also been a common practice in Korea. Korea's inter-generational family structures have both allowed elderly parents to rely on their children for housing and enabled them to help their children with household chores. Traditionally, the eldest son in a family was responsible for taking care of his parents (Park et al., 2006).

While the parents' expectations for their children remain, the sudden erosion of traditional values has resulted in a decline in the support adult children provide their elderly parents, leaving those parents financially unprepared after they retire. Above all, the norm of filial piety has changed over the generations. Traditionally, the central goal of hyo for children was to behave in a manner that made their parents happy. Although this remains a recognized social value, the younger generation seems to increasingly emphasize their elderly relatives' personal responsibility for their own care. The elderly generation also has different perceptions of hyo. Indeed, these days, elderly parents are less likely to take their children's care for granted. This derives from the fact that the elderly value emotional forms of support more than material forms. The elderly in Korea appear to view their reliance on their children not as their children's duty (Park et al., 2006). Such perceptions from both generations have contributed to the weakening of traditional customs. 
Another cause of the decline in private transfers to the elderly is Korea's declining birth rate. Korea's average birth rate was 6.1 in 1960 and 5.1 in 1965 . This high birth rate made it possible for elderly parents to rely solely on their children's support. From the 1960s to the 1980s, when Korea underwent rapid economic growth, the Korean government established the goal of reducing the birth rate (Choi, 2009). Thus, it initiated campaigns emphasizing smaller family units - "two-children families." As a result, the birth rate fell from 4.53 in 1970 to 1.57 in 1990 and then to 0.98 in 2018 (Statistics Korea, 2019). This means that fewer children now bear the responsibility of financially supporting their parents than in the past when more than four adult children could share this responsibility. Thus, the decline in the birth rate negatively affected private transfers and the familial support provided to elderly parents.

The share of private transfers, including support from adult children, has decreased significantly over the past decades (OECD, 2001: 85). Throughout the 1980s, about 30 percent of the income of elderly Koreans aged 60 and over came from private transfers, equaling 33.8 percent in 1987. This highlights the importance of private transfers as sources of income for elderly Koreans. After the economic crisis in late 1990s, the ratio of elderly income from private transfers declined, falling to 15.1 percent in 2005. In contrast to the decrease in overall private transfers in elderly income, the share of public transfers in the elderly income rose precipitously during the 1990s as a result of the distribution of the first benefits from the National Pension System (NPS). The ratio of public transfers divided by current income was as low as 1.5 percent in 1982, but by 1993, it had risen to 25.3 percent and it reached 31.6 percent in 1994; subsequently, throughout the 1990s, it remained in general between 25 and 35 percent (Kang, 2008).

Table 4 shows the sources of monthly average elderly income between 2012 and 2017 . The share of private transfers in elderly income decreased from 7.9 percent in 2012 to 5.3 percent in 2017. Due to the implementation of the Basic (Old-age) Pension in 2008 and the change in the basic pension policy, the contribution of public pensions increased over the past decade. That is, the share of public transfers in elderly income rose from 19.3 percent in 2012 to 22.3 percent in 2017. Nonetheless, the increase in public transfers has not been sufficient to offset the loss of private transfers (Kwon, 2001). Since poorer elderly households are likely to rely more on private transfers, it can be concluded that poorer elderly population have become more vulnerable to poverty.

Table 4. Sources of elderly income aged 60 or over

\begin{tabular}{lll} 
& \multicolumn{2}{c}{ (unit: 10,000 Korean won) } \\
\hline & 2012 & 2017 \\
\hline earned income & 823 & 1,235 \\
business income & 591 & 679 \\
property income & 293 & 337 \\
public transfer & 453 & 692 \\
private transfer & 185 & 164 \\
\hline current income & 2,345 & 3,107
\end{tabular}

Source: Statistics Korea, Bank of Korea, Financial Supervisory Service, Household Financial Welfare Survey, 2019

The increase in the number of elderly people living alone or separate from their adult children is also evidence of declining family support and the weakening of inter-generational ties. Co-residence among generations was once a social norm. In 1994, 54.7 percent of the elderly population lived with their adult children. However, the number of elderly parents living separately from their children quickly increased in the late 1990s and the early 2000s. By 2004, the ratio of elderly parents co-residing with their adult children had decreased to 38.6 percent; by 2017, the ratio had decreased still further to 23.7 percent when about 72 percent of the elderly individuals were reported to live alone or just with their marital partners (Jung, 2018).

Thus, the Korean family structure transformed from the traditional large extended family to the small and individualized unit in a relatively short period of time. Urbanization led married or employed children to live elsewhere, while elderly people in general remained in their previous residences in the rural sector. The unprecedented decline in support from adult children has left many elderly individuals with additional financial burdens. Also notable is the increase in the number of elderly individuals who live on their own - further evidence of 
declining familial support. Moreover, many elderly Koreans suffer neglect from their children after the deaths of their marital partners (Jung, 2012).

Although most old persons who live alone rely primarily on subsidies provided by the National Basic Livelihood Security Act, these subsidies are minimal. Shelters and assistance from public facilities are only provided to poor members of the elderly population who do not have children. However, despite the fact that most elderly people living alone have relatives and children, most are unable to reach out for help. Moreover, elderly individuals who live alone have relatively less contact with their relatives and children than elderly couples, making them more vulnerable to poverty, isolation, and illness. They are thus both vulnerable to poverty and excluded from public support (Kang and Lee, 2018).

Views on the role of the government and society in supporting the elderly have also changed rapidly over the past decades; this can be at least partly attributed to decreasing private transfers from families. In 1998, 89.9 (2.0) percent of surveyed respondents believed that adult children (the society) should be the main sources of income for their elderly parents; ten years later, in 2008, just 40.7 (43.6) percent of them believed that adult children (government, society and adult children) should be the main sources of income for their elderly parents (Statistics Korea, 2012). The figure had declined to just 26.7 by 2018 (Statistics Korea, 2018). This highlights the rapid change in beliefs regarding the responsibility to care for the elderly in Korea.

Economic development and westernization expanded individualism and urbanization, further weakening traditional values. One main issue was the fact that many elderly individuals were unable to accumulate sufficient savings for their post-retirement lives because of the large sums they spent on the education of their children. Despite parents' expectations of financial support from their children, adult children of the new generation have different perspectives when it comes to supporting their parents financially. Nevertheless, the concept of saving and preparing for post-retirement life is relatively new in Korea and the older generation had too little time to prepare financially. They spent most of the income they earned on their children over the years, leaving them financially unprepared for retirement (OECD, 2014).

In a 2013 survey regarding financial preparation for post-retirement, only 51.6 percent of respondents aged 60 or over replied that they were prepared for post-retirement. In other words, almost half of respondents replied that they were financially unprepared to support themselves. Of the respondents, 56.1 percent selected their financial circumstances as the main reason for their lack of preparedness, while about 31.7 percent of them replied that they expected financial support from their children (Statistics Korea, 2013). This indicates that many of these individuals did not accumulate wealth during their working years because they believed their children would support them financially.

Moreover, the introduction of social welfare systems has further decreased children's sense of responsibility for supporting their parents. As social awareness regarding this issue has increased, public transfers have expanded over the years. Thus, the younger generation now expects the government to play the traditional role of adult children in supporting the elderly. Meanwhile, the public welfare system of Korea still has many limitations

\section{Public Transfer}

When the economic crisis hit, the real GDP growth rate of Korea declined abruptly to -6.9 percent in 1998 and the unemployment rate jumped from lower than 3 percent during the early to mid-1990s to over 6 percent in 1998 and 1999. In the process of recovering from the economic crisis, the Korean government implemented various neo-liberal reform measures and the divisions between the "haves" and "have-nots" have worsened in Korea since the economic crisis. Although the Gini coefficient remained below 0.28 during the early to mid-1990s, it rose to 0.32 in 1999 and remained above 0.3 during the 2000s (Park and Mah, 2011:249-260). Moreover, elderly poverty became one of the main social agendas.

Consequently, particularly since the late 1990s, the Korean government has emphasized the establishment of social welfare programs to ensure income and provide basic social welfare to the elderly. Pension schemes have served as particularly effective instruments of social welfare in relieving the financial difficulties of the elderly. Current Korean pension plans operate under a multi-pillar framework, where private and public pensions work to curb elderly poverty (Kim, 2012). Although the public transfer system was introduced in the late 1980s to provide income for the elderly, the share of public transfers in the income of elderly individuals in Korea has remained among the lowest in OECD countries.

Table 5 compares the income sources of the elderly among various OECD members, showing that the share of public transfers in the income of the elderly was the lowest in Korea (15.2 percent) and Finland (14.9 percent). Meanwhile, 
income from work accounted for 58.4 percent of the income of the elderly in Korea, the highest level among all the OECD members. This implies that many elderly Koreans continue working to make a living.

Table 5. Comparison of the income sources of the elderly in the mid-2000s

\begin{tabular}{llll}
\hline country & public transfer & work & capital \\
\hline France & 86.7 & 6.4 & 6.9 \\
Hungary & 85.6 & 11.8 & 2.6 \\
Poland & 78.4 & 20.6 & 1.0 \\
Czech Republic & 75.9 & 23.6 & 0.5 \\
Germany & 74.9 & 9.9 & 15.2 \\
Italy & 72.5 & 23.6 & 4.0 \\
Spain & 70.8 & 24.1 & 5.1 \\
U.K. & 49.8 & 11.9 & 38.3 \\
Japan & 48.3 & 44.4 & 7.3 \\
Canada & 46.7 & 13.4 & 39.9 \\
Turkey & 46.3 & 40.9 & 12.8 \\
U.S. & 35.4 & 34.3 & 30.3 \\
Korea & 15.2 & 58.4 & 26.4 \\
Finland & 14.9 & 11.2 & 73.9 \\
\hline
\end{tabular}

Source: OECD. (2009). Pensions at a Glance.

Due to the short history of the Korean pension system, it is not yet fulfilling its role as a mechanism to secure appropriate incomes for the elderly. In addition, the Korean government has long prioritized economic growth, leading it to minimize its provision of social welfare to the unprivileged. Until recently, expenditures on elderly welfare accounted for only 0.4 percent of the total budget of the government (Kim and Cook, 2011). The national pension policies introduced in late 1990s and 2000s did not truly reflect the changes occurring in Korean society, thus exposing many elderly people to poverty. This is mainly due to the fact that pension systems require long periods of time to develop. Unlike most developed countries, which have succeeded in establishing solid and effective welfare systems by accumulating financial resources over long periods of time, the funds Korea has accumulated cannot adequately satisfy most beneficiaries (Jones and Urasawa, 2014).

Construction of the Korean multi-pillar pension scheme began with the independent development of each pension plan. In 1988, the NPS was introduced and quickly became the main source of income for the elderly. Its objective is to provide a stable source of income to elderly individuals along with special occupational pensions (Kim et al., 2005). After the outbreak of the economic crisis in late 1990s, the economic situation of poor people worsened due to the absence of a social safety net. This led to the reform of the NPS together with the introduction of the Basic Livelihood Security Program and the Basic Old-age Pension Scheme. The 1999 reform contained several progressive elements. For instance, the National Basic Livelihood Act was designed to guarantee people the right to a minimum income, implying the recognition of social welfare as a right (Jung, 2009).

Moreover, the government started to consider the interrelationships among the different pension schemes and their roles, which led to the amendment of the National Pension Act in 1998. The government emphasized the reinforcement of two types of pensions by coordinating the role of each pension scheme. Fiscal sustainability, narrow coverage, and inequality were the main issues the NPS sought to address and they were therefore covered in this amendment. After its initial establishment, the NPS thus began to solidify its position as a universal public pension plan. In the initial stage of its establishment, the NPS targeted employees aged 18-59 at workplaces with more than 10 employees. In the late 1990s, its coverage expanded. In 2000, the Basic Livelihood Security Program was introduced with the aim of reducing the number of people below the absolute poverty line by granting a minimum income (Kim et al., 2005). 
Korea's pension system subsequently evolved to focus on the establishment of a systematic multi-pillar pension scheme that supplemented each plan. Consequently, the issue of reducing the poverty of the elderly population-a population not included in the NPS - became increasingly urgent. This led to the need to devise another scheme that would resolve poverty traps for the elderly who were not eligible for the NPS. Thus, the Basic Old-age Pension, the Basic Pension since 2012, was implemented in 2007 with the objective of addressing the current limitations of the NPS. It has provided public assistance to individuals aged 65 or over who meet certain criteria (Kim et al., 2005).

As of 2019, the first tier of the pension system consists of the NPS and the occupational pension schemes. The retirement allowance and the company pension system form the second tier, and individual pension accounts comprise the third tier. Meanwhile, the zero pillar provides social welfare programs that address poverty, such as the Basic Livelihood Security Program and the Basic Pension (OECD, 2014). Each pension system has a distinct role in promoting elderly income security. While the NPS is defined as a universal pension plan that targets a broad population, the Basic Livelihood Security Program and the Basic Pension specifically aim to alleviate the difficulties faced by poor citizens.

\subsection{National Pension System (NPS)}

The NPS was first established in 1988 as a contributory social insurance scheme. It initially covered employees working for companies with 10 or more employees, but its coverage later expanded to fulfill its original purpose as a universal public pension system. It became the nationwide pension scheme for all workplaces with one or more workers, indicating that the coverage has increased rapidly over the years. Contributions to the NPS became mandatory in 1999 (OECD, 2016a). The number of participants increased from 4,433,000 in 1988, to 16,260,000 in 1999, and then to 22,313,000 in 2018 (National Pension Service, 2019).

Reflecting the increasing number of contributors to the NPS, the share of contributors in the working-age population increased from lower than 20 percent through 1994 to 32.5 percent in 1999 . Thereafter, the percentage gradually increased during the 2000s, reaching 43.4 percent in 2012, still well below the 80-100 percent shares recorded in the other developed countries. This reflects low compliance by self-employed and non-regular workers in small- and medium-sized enterprises (Lee and Phillips, 2012). In 2012, the ratio of labor force contributors reached 66.4 percent (OECD, 2014). Despite the increase in the number of NPS contributors, the NPS still has important limitations. In particular, many vulnerable groups are either excluded from coverage or refuse to contribute. Low participation rate, narrow coverage, and limitations in the coverage of vulnerable groups are the three main issues remaining in the Korean NPS (OECD, 2016a).

Regarding types of employment, in 2011, 33.0 percent of self-employed persons and 19.7 percent of regular employees did not participate in the NPS (Statistics Korea, 2011). The high rate of nonparticipation among self-employed persons can be attributed to the fact that many of them rely on unstable incomes, thus making it more difficult to contribute to the pension plan on regular bases over long periods of time. Moreover, unstable incomes prevent many self-employed persons from contributing for the requisite numbers of years, excluding them from post-retirement benefits. Consequently, many self-employed and non-regular workers do not participate in the NPS.

Regarding the reasons for the public's nonparticipation, about half of the respondents to a survey conducted by KIHASA replied that they could not afford the pension scheme. The other half replied that they see no reason to participate. Only about 3 percent of the respondents selected distrust in the pension scheme as the reason for their nonparticipation (KIHASA, 2019). Therefore, the financial burden of contributions and the public's view of public pensions as an unnecessary practice are the two main reasons for nonparticipation in the scheme.

The NPS' limited coverage is also notable. In 2015, 47.8 percent of nonparticipants did not contribute to the NPS because their ages made them ineligible for it (Statistics Korea, 2015). Due to the NPS' rather recent implementation, members of the current elderly population were unable to make contributions, and therefore have been excluded from the coverage policy. Moreover, the minimum requirement of 10 years of contributions to the NPS naturally excludes workers with non-regular incomes from coverage and benefits (Choi, 2002). In 2016, although the NPS covered 98.2 percent of regular workers, it only covered 56.7 percent of non-regular workers (OECD, 2018: 49).

The NPS contribution rate of Korea has remained at 9 percent since 1998 (OECD, 2018: 32). As Table 6 shows, this is one of the lowest percentages among the OECD members. Indeed, the average contribution rate of OECD members reached 19.6 percent in early 2010s. This shows that the share of public transfers in elderly income in Korea is very low. Insufficient contribution rates and low participation also create problems in the financing of the NPS. Funding issues are important because they are directly related to the amounts beneficiaries receive. Other limitations to the current NPS are its low benefits and issues related to its sustainability (OECD, 2014). The average 
pension benefit provided by the NPS was small at 461,000 Korean won per month (about US\$323), less than 30 percent of the median income level in 2018, 1,672,000 Korean won (Ministry of Health and Welfare, 2017; NPS, 2019). Thus, pension benefits fall short of covering the basic living expenses of elderly people in Korea. The above-mentioned issues limit the NPS' impact in alleviating poverty among the elderly in general.

Table 6. Comparison of the contribution rates in the national pension system

(unit: percent)

\begin{tabular}{llll}
\hline Country & employee & employer & total \\
\hline Hungary & 10.0 & 24.0 & 34.0 \\
Italy & 9.2 & 23.8 & 33.0 \\
Spain & 4.7 & 23.6 & 28.3 \\
Czech Republic & 6.5 & 21.5 & 28.0 \\
Australia & 10.3 & 12.6 & 22.9 \\
Turkey & 9.0 & 11.0 & 20.0 \\
Poland & 9.8 & 9.8 & 19.6 \\
Germany & 9.8 & 9.8 & 19.6 \\
Japan & 8.4 & 8.4 & 16.8 \\
France & 6.8 & 9.9 & 16.7 \\
USA & 4.2 & 6.2 & 10.4 \\
Canada & 5.0 & 5.0 & 10.0 \\
Korea & 4.5 & 4.5 & 9.0 \\
Israel & 3.9 & 3.1 & 7.0 \\
\hline OECD average & 8.4 & 11.2 & 19.6 \\
\hline
\end{tabular}

Source: OECD. (2013). Pensions at a Glance.

\subsection{The Basic (Old-Age) Pension Scheme and the Basic Livelihood Security Program}

The Basic Old-age Pension Scheme, one of the main non-contributory public pension schemes, was introduced in 2008 with the objective of mitigating poverty of elderly individuals who had no chance to join the NPS. As of 2019, it was renamed the Basic Pension. Since it aims to reinsure income for elderly people in poverty, it should have been devised as a low-coverage, high benefit system (Yoon, 2012). Meanwhile, it has the highest coverage level among OECD members. Most OECD members have operated targeted coverage for such pension schemes at rates under 50 percent. Japan has a highly targeted coverage rate of only 2 percent and the United States has a coverage rate of 7 percent of elderly people. Korea maintained an unusually high coverage rate of about 78 percent from 2012-2017. In 2017, the number of beneficiaries of the Basic Pension Scheme reached 3.7 million and 78.6 percent of the elderly were beneficiaries (Statistics Korea, 2018). Although countries such as Denmark (88 percent) and Australia (78 percent) have high coverage rates for elderly individuals aged 65 or over, most other nations with high coverage rates (except Denmark) also provide high benefits because they have sufficient financial resources (OECD, 2014).

Another challenge of the Basic Pension Scheme is the low level of benefits it provides. High benefits are crucial for the Basic Pension Scheme to properly function, but the benefits it provides are too low to relieve the current poverty of the elderly in Korea. The benefit level was initially set at 84,000 Korean won (US\$76) for single-member household or 134,000 Korean won (US\$121) for couples in 2008. This was only 5 percent of the NPS participants' average monthly income, 1,677,000 Korean won (US\$1,520) (Moon, 2008). As of August 2019, elderly individuals aged 65 or over qualify as beneficiaries. The highest monthly benefit from the Basic Pension System now equals 400,000 Korean won (about US\$330) for couples and 250,000 Korean won (about US\$210) for single-member households (Ministry of Health and Welfare, 2019). 
The Basic Livelihood Security Program (BLSP) has the same low benefit problem. It provided benefits of only 6 percent of average earning in 2015, the second lowest of all OECD members and way below the per capita GDP (OECD, 2015b). Moreover, the strict criteria applied in the BLSP do not reflect societal changes and, as a result, limit its impact as a social welfare program. It aims to ensure a minimum cost of living to beneficiaries under the absolute poverty line and provides benefits to about 3 percent of the population. However, considering the fact that 7-8 percent of Koreans have incomes below the minimum cost of living, its coverage is clearly very limited. The BLSP eligibility criteria in Korea include asset ownership, which is converted into property income. Moreover, those with the possibility of assistance from family or relatives are automatically ineligible for benefits due to the "family support obligation rule." The eligibility criteria were relaxed in 2012 and the benefits amounts increased beginning in October 2014 (Jones and Urasawa, 2014).

\section{Conclusions and Policy Implications}

Korea's rapid economic growth since the mid-1960s led to a remarkable increase in its per capita GDP. Meanwhile, a reduced birth rate and the aging of the population, among other factors, led to very high poverty rates among the elderly. The fact that a society long governed by the Confucian idea of respect for the elderly and a tradition of adult children financially supporting their elderly parents has such a high elderly poverty rate is ironic. Decrease in the number of adult children per family from more than 5 prior to the 1960 s to only about 1 by the 2010 s rendered adult children unable to share the burden of supporting their elderly parents. In addition, the decreasing birth rate has been accompanied by unprecedentedly rapid population aging, meaning that numbers of post-retirement years have increased significantly. These phenomena have led to reductions in private transfer levels from adult children to their elderly parents.

To relieve the economic difficulties faced by retirees, the Korean government introduced the National Pension System (NPS) in 1988, initiating a system of public transfer for elderly Korean. Although the operation of the NPS has gradually improved, it still has some important limitations in supporting the elderly. Among other limitations, the number of recipients is relatively lower than in other OECD member countries and the pensions recipients receive are too small, on average, to support them. In addition, in Korea, the overall rate of contribution to the NPS remains quite low. Policymakers need to try to persuade citizens to accept heavier NPS contribution burdens. If the contribution rate does not rise, Korea's NPS may go bankrupt a few decades later. Moreover, the NPS participation rate in Korea remains low compared to other countries with similar levels of economic development. Thus, Korea also needs to reinforce participation in the NPS.

The NPS is supplemented by non-contributory welfare schemes such as the Basic Pension Scheme and the Basic Livelihood Security Program (BLSP). The Basic Pension Scheme was introduced with the objective of mitigating poverty among the elderly. It has maintained an unusually high coverage rate, which means that the amount that each recipient can receive is too small to cover the living expenses of the poor elderly. Reducing the number of the beneficiaries in the Basic Pension Scheme and allocating the limited funds to the poor elderly would be worthwhile. Another problem with the BLSP is the low level of benefits it provides. The highest monthly benefit it provides is much lower than the minimum cost of living. The BLSP aims to ensure that it provides a minimum cost of living to beneficiaries under the absolute poverty line; however, its coverage is highly limited and many vulnerable groups are ineligible to receive benefits.

Thus, Korea has a very high elderly poverty ratio due to decreasing private transfer levels and the lack of adequate support from public transfers. Korea's experience has important policy implications for developing countries that will face similar problems. Developing countries with very high economic growth rates are likely to experience population aging and the increasing nuclearization of families. Rapid population aging, in particular, is likely to create serious elderly poverty problems. Therefore, developing countries must gradually introduce appropriate public transfer systems beginning during the early stages of rapid economic growth and modernization. Although institutions, including longstanding cultural traditions, do not change rapidly in general, Korea's case shows that the process of rapid economic growth can lead to rapid changes in culture and customs. For instance, although the Confucian cultural tradition of adult children showing respect for the elderly and providing their elderly parents financial support was deeply engrained in Korea, the country's rapid economic growth since the mid-1960s has caused this longstanding culture to fade away. This paper may have limits in the sense that the implications derived from the case of Korea may not be appropriate for the other societies with different culture and economic development experiences. Therefore, it would be worthwhile to analyze the issue of the poverty of the elderly with respect to the societies other than Korea. 


\section{References}

Choi, H. (2002). Inequality and Poverty Arising from the Blind Spots of the National Pension System. Journal of the Korea Gerontological Society, 22(3), 223-243 (in Korean).

Choi, S. J. (2009). Ageing Society Issues in Korea. Asian Social Work and Policy Review, 3(1), 63-83. https://doi.org/10.1111/j.1753-1411.2008.00025.x

Hwang, N. (2015). Ageing Society and the Change in the Role of Public and Private Transfers. Health and Welfare Issue and Focus, 287. Seoul: Korea Institute for Health and Social Affairs (KIHASA) (in Korean).

Jones, R. S., \& Urasawa, S. (2014). Reducing the High Rate of Poverty Among the Elderly in Korea. OECD Economics Department Working Papers.

Jung, I. Y. (2009). Explaining the Development and Adoption of Social Policy in Korea: The Case of the National Basic Livelihood Security Act. Health and Social Welfare Review, 29(1), 52-81. https://doi.org/10.15709/hswr.2009.29.1.44

Jung, K. H. (2018). Older Koreans and Their Families: Current Status and Future Prospects. Health and Welfare Forum, 264, 6-18 (in Korean).

Kang, E., \& Lee, M. (2018). Analysis on the Effect of Living Alone During the Old-Age: Comparison of Elders Living Alone and Those Who Do Not Through Propensity Score Matching Methods. Health and Social Welfare Review, 38(4), 196-226 (in Korean).

Kang, S. (2008). Changes in Public Transfer Affected by Changes in People's Attitudes Forwards Intergenerational Family Support. Health and Welfare Forum, 144: 65-76 (in Korean). https://doi.org/10.15709/hswr.2018.38.4.196

KIHASA. (2019). Korean Welfare Panel Survey. Retrieved from http://kosis.kr/statisticsList/statisticsListIndex.do?menuId=M_01_01\&vwcd=MT_ZTITLE\& parmTabId=M_01_01\&parentId= D.1; D3.2;331_33109.3;331_33115.4;\#331_33109.3 (in Korean)

Kim, E. H., \& Cook, P. J. (2011). The Continuing Importance of Children in Relieving Elder Poverty: Evidence from Korea. Ageing and Society, 31(6), 953-976. https://doi.org/10.1017/S0144686X10001030

Kim, S., Kim, S., \& Ahn, S. (2005). Research on the Establishment of the Multi-Pillar Income Security of the Elderly. Research Report 2005-05. Seoul: National Pension Service Research Institute (in Korean).

Kim, W. S. (2012). Structural Solutions to an Efficient Multi-Pillar Elderly Income Security System of the NPS. Insurance Finance Research, 23(4), 61-98 (in Korean).

Korea Institute for Health and Social Affairs (KIHASA). (2017). 2017 Elderly Survey. Seoul: KIHASA (in Korean).

Kwon, S. (2001). Economic Crisis and Social Policy Reform in Korea. International Journal of Social Welfare, 10, 97-106. https://doi.org/10.1111/1468-2397.00159

Lee, J., \& Phillips, D. (2011). Income and Poverty among Older Koreans: Relative Contributions of and Relationship between Public and Family Transfers. Rand Corporation working paper. https://doi.org/10.7249/WR852

Ministry of Health and Welfare. (2017). Ministry of Health and Welfare Notice 2017-139. Retrieved from https://www.mohw.go.kr/react/jb/sjb0406vw.jsp

Ministry of Health and Welfare. (2019). What Is the Basic Pension?. Ministry of Health and Welfare website. Retrieved August 29, 2019, from http://basicpension.mohw.go.kr (in Korean)

Moon, H. (2008). The Role of Social Pensions in Korea. Paper presented at World Bank-MOF-Hitotsubashi Workshop, February, Tokyo.

National Pension Service. (2019). National Pension Statistical Yearbook 2018. Jeonju-si: National Pension Service (in Korean).

OECD (2019b). Poverty Rate. Retrieved August 27, 2019, from http://data.oece.org/inequality/poverty-rate.htm

OECD. (2005, 2015a, 2016b). Society at a Glance. Paris: OECD.

OECD. (2009, 2013, 2015b, 2017). Pensions at a Glance: OECD and G20 Indicators. Paris: OECD.

OECD. (2019a). Database on Income Distribution and Poverty. Retrieved July 8, 2019, from https://www.oecd.org/social/income-distribution-database.htm 
Organisation for Economic Co-operation and Development. (2001, 2014, 2016a, 2018). OECD Economic Surveys: Korea. Paris: OECD.

Park, J., \& Mah, J. (2011). Neo-liberal Reform and Bipolarisation of Income in Korea. Journal of Contemporary Asia, 41(2), 249-265. https://doi.org/10.1080/00472336.2011.553044

Park, K.-S., Phua, V., Mcnally, J., \& Sun, R. (2006). Diversity and Structure of Intergenerational Relationships: Elderly Parent-Adult Child Relations in Korea. Journal of Cross-Cultural Gerontology, 20(4), 285-305. https://doi.org/10.1007/s10823-006-9007-1

Statistics Korea, Bank of Korea and Financial Supervisory Service. (2019). Household Financial Welfare Survey, Retrieved July 21, 2019, from http://kostat.go.kr/portal/korea/kor_nw/1/4/4 /index.board (in Korean)

Statistics Korea. (2011). Working Population Survey (retrieved August 8, 2019) (in Korean).

Statistics Korea. (2012, 2013, 2015, 2018). Social Survey (in Korean).

Statistics Korea. (2019). Demographic Trend, Retrieved July 17, 2019, from http://kosis.kr (in Korean)

United Nations Economic and Social Commission for Asia and the Pacific (UNESCAP). (2016). Income Security for Older Persons in the Republic of Korea. SDD-SPPS Project Working Paper. Bangkok: UNESCAP.

Yoon, S. (2012). The OECD Proposal on Korean Pension Reform Direction: The Past and Now. Health and Social Welfare Forum. Seoul: KIHASA (in Korean).

\section{Copyrights}

Copyright for this article is retained by the author(s), with first publication rights granted to the journal.

This is an open-access article distributed under the terms and conditions of the Creative Commons Attribution license (http://creativecommons.org/licenses/by/4.0/). 